\title{
Streptococcus suis in Swedish grower pigs: occurrence, serotypes, and antimicrobial susceptibility
}

\author{
Anna Werinder ${ }^{*^{*} \mathbb{D}}$, Anna Aspán², Annette Backhans ${ }^{3}$, Marie Sjölund ${ }^{3}$, Bengt Guss ${ }^{4}$ and Magdalena Jacobson ${ }^{1}$
}

\begin{abstract}
Background: Streptococcus suis is a major cause of meningitis, arthritis, and pneumonia in pigs worldwide, and an emerging pathogen in humans. In Sweden, S. suis has previously received little attention but has in recent years become increasingly recognized as affecting the pig production. The aim of the present study was to investigate the occurrence, serotypes and antimicrobial susceptibility of S. suis in Swedish grower pigs from herds with and without reported S. suis associated disease, as well as possible associations between S. suis associated disease and selected environmental and production factors. Swab samples were taken from the tonsils of clinically healthy 8-13-week-old grower pigs from ten case herds and ten control herds. Isolates were cultured, identified using MALDI-TOF MS, and serotyped using latex agglutination. The antimicrobial susceptibility of 188 isolates was tested using broth microdilution. Production data was gathered and environmental parameters were measured on the farms.

Results: Streptococcus suis was isolated from $95 \%$ of the sampled pigs in both the case and the control herds. Serotypes $3,4,5,7,9,10,11,15,16$, and 17-34 were detected, although a majority of the isolates (81.5\%) were non-typeable. There was less diversity among the serotypes isolated from the case herds than among those from the control herds; four and nine different serotypes, respectively. Isolates resistant to penicillin (3.8\%) were reported for the first time in Sweden. Tetracycline resistance was common (88.4\%). No association was noted between the production and the environmental factors investigated, and the carriership of S. suis.

Conclusions: The carriership of S. suis was found to be higher in clinically healthy Swedish pigs than previously estimated, and for the first time, the presence of Swedish isolates resistant to penicillin was reported. Many of the most commonly disease-associated serotypes, e.g. serotypes 2, 9, 3, and 7, were detected in healthy grower pigs although further studies are needed to investigate the virulence of these isolates.
\end{abstract}

Keywords: Antibiotic resistance, Bacteria, Environmental factors, Infectious diseases, Meningitis, Microbiology, Porcine, Streptococci, Swine, Zoonosis

\section{Background}

Streptococcus suis is considered one of the most important pathogens affecting pig production worldwide and is also an emerging zoonotic agent in humans. In both

*Correspondence: anna.werinder@slu.se

${ }^{1}$ Department of Clinical Sciences, Swedish University of Agricultural Sciences (SLU), Box 7054, 75007 Uppsala, Sweden

Full list of author information is available at the end of the article humans and pigs, S. suis may cause meningitis, sepsis, arthritis, pneumonia, endocarditis, and acute death [1, 2]. Pigs carry the bacteria in the tonsils and on the nasal mucosa, as well as in the gastrointestinal and genital tracts $[3,4]$, and healthy carrier animals are thought to be present on most pig farms. Transmission of bacteria between pigs occurs mainly via the respiratory route [5], and from sows to piglets at birth [6].

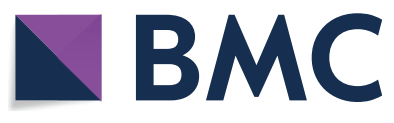

(c) The Author(s) 2020. This article is licensed under a Creative Commons Attribution 4.0 International License, which permits use, sharing, adaptation, distribution and reproduction in any medium or format, as long as you give appropriate credit to the original author(s) and the source, provide a link to the Creative Commons licence, and indicate if changes were made. The images or other third party material in this article are included in the article's Creative Commons licence, unless indicated otherwise in a credit line to the material. If material is not included in the article's Creative Commons licence and your intended use is not permitted by statutory regulation or exceeds the permitted use, you will need to obtain permission directly from the copyright holder. To view a copy of this licence, visit http://creativeco mmons.org/licenses/by/4.0/. The Creative Commons Public Domain Dedication waiver (http://creativecommons.org/publicdomain/ zero/1.0/) applies to the data made available in this article, unless otherwise stated in a credit line to the data. 
Environmental factors such as higher outside temperature, excessive temperature fluctuations, and high air relative humidity have been associated with a higher proportion of S. suis carriership, as have production factors such as crowding and continuous production systems [7, 8]. Further, infection with porcine reproductive and respiratory syndrome (PRRS) virus may predispose pigs to secondary S. suis-infections [9].

Presumptive diagnosis in pigs is based on clinical signs and should be confirmed by necropsy and isolation of the pathogen. S. suis is a phenotypically and genetically diverse species with a complex taxonomy and may be challenging to accurately identify in the laboratory. Based on the antigenicity of the polysaccharide capsule, 35 serotypes were initially described, although sequencing of the $16 \mathrm{~S}$ rRNA and cpn60 genes has more recently indicated that six of these belong to other species [10-12]. The serotypes most commonly isolated from diseased pigs are 2, 9, 3, 1/2, and 7 [13], and individual pigs frequently carry more than one serotype $[14,15]$. Relatively high levels of resistance to some antimicrobials (e.g. macrolides, lincosamides, tetracyclines, and sulphonamides) have been reported in many countries, while resistance to penicillins has generally been described as low [16].

Although the first Swedish reports of S. suis-infections in pigs and humans were published in the mid-1980s [17, 18], this pathogen has until recently received little attention. However, two more human cases were reported in $2014[19,20]$, and veterinarians in clinical practice have noticed an increase in pigs showing clinical signs indicative of S. suis-infection. Therefore, the aim of this study was to investigate the occurrence, serotypes and antimicrobial susceptibility of $S$. suis in Swedish grower pigs from farms with and without reported disease, as well as possible associations with selected environmental and production factors.

\section{Methods}

The study was approved by the Ethics Committee for Animal Experimentation, Uppsala, Sweden (Dnr 5.8.18-15404).

\section{Study design}

A case-control design was used. Herds were chosen based on the referrals of herd health veterinarians from the Swedish "Farm \& Animal Health" service that covers $80 \%$ of the Swedish pig herds. The case group included ten pig herds where the health-service veterinarian had previously diagnosed S. suis-infections and clinical signs had been noted in several batches of weaned pigs during the year preceding the sampling. An equal number of herds where no such diagnoses had ever been made by the herd health veterinarians were used as controls.
No selected herds opted out of participating. For the purposes of this study, clinical signs indicative of S. suisinfection were defined as grower pigs (from weaning to $30 \mathrm{~kg}$ body weight) circling or exhibiting seizures, lateral recumbency with paddling leg movements, or severe pneumonia in herds where S. suis pneumonia had previously been laboratory confirmed.

\section{Herds}

The samples were collected during 2018 and 2019 from 20 farms located in the south and central parts of Sweden, in the counties with the highest pig density. The herds included piglet producing, farrow-to-finish, and gilt producing conventional herds, as well as piglet producing and farrow-to-finish organic herds, and piglet producing and farrow-to-finish sow pool satellites (i.e., a multi-site production system with a central unit for mating and pregnant sows, and several satellite herds where farrowing and piglet production takes place [21]). In accordance with the Swedish legislation [22], growthpromoting antibiotics or growth-promoting hormones were not used. Further, the Swedish pig production is declared free from PRRS virus, and an active surveillance programme is in place [23].

\section{Data collection}

In each farm, environmental measurements were collected from the room housing the targeted pigs. Temperature and air relative humidity were measured at the height of approximately $1 \mathrm{~m}$ in the middle of the room using a Testo 625 thermohygrometer (Testo SE \& Co. KGaA, Lenzkirch, Germany). The air velocity was measured at the height of approximately $0.1 \mathrm{~m}$ in $2-6$ randomly distributed pens per room, adjacent to the solid and to the slatted floor areas (or, where applicable, adjacent to the deep straw bedding), using a Testo 405-V1 thermal anemometer (Testo SE \& Co. KGaA). Carbon dioxide was measured at the height of approximately $1 \mathrm{~m}$ in the middle of the room and ammonia was measured at the height of approximately $0.1 \mathrm{~m}$ adjacent to the slatted floor area in 4-6 randomly distributed pens per room, (or, where applicable, adjacent to the deep straw bedding), using colorimetric detector tubes and a manual GV-100 air sampling pump (GASTEC Corporation, Kanagawa, Japan).

Information on management practices and production data covering 1 year before sampling was obtained from the farmers through interviews and from the farm management software PigVision (AgroVision B.V., Deventer, Netherlands). All data collection was performed by the first author. Mean values for the case and control group were compared using a two-tailed $\mathrm{t}$-test, and $\mathrm{P}<0.05$ was 
considered significant. Statistical analysis was performed in $\mathrm{R}$ version 3.6.2 [24].

\section{Bacterial sampling}

From each farm, samples were taken from ten clinically healthy grower pigs from the same batch, if possible from one pig per pen. The pigs were $8-13$ weeks of age and had not been subjected to any treatment for at least 1 month before sampling. The pigs had all been weaned at between 4 and 6 weeks of age [25]. A sample was obtained from each pig's palatine tonsils by opening the mouth using snares of braided nylon rope around the upper and lower jaws and rubbing an eSwab ${ }^{\mathrm{TM}} 480 \mathrm{CE}$ (Copan Diagnostics, Inc., Corona, CA, USA) on the tonsillar surface for $3 \mathrm{~s}$. The swabs were immediately placed in tubes containing liquid Amies transport medium, transported to the laboratory at ambient temperature, and were processed for bacteriological analysis within $18 \mathrm{~h}$ of sampling.

\section{Bacterial isolation and identification}

The swabs were streaked directly onto streptococcal selective colistin-oxolinic acid-blood agar (COBA) plates (National Veterinary Institute, Uppsala, Sweden), and incubated at $37{ }^{\circ} \mathrm{C}$ in $5 \% \mathrm{CO}_{2}$ overnight. From each sample, 5-12 small, translucent colonies exhibiting $\alpha$ - or $\beta$-hemolysis [26] were subcultivated on $5 \%$ horse blood agar plates (National Veterinary Institute) and incubated at $37{ }^{\circ} \mathrm{C}$ in $5 \% \mathrm{CO}_{2}$ overnight. Following incubation, matrix-assisted laser desorption ionizationtime of flight mass spectrometry (MALDI-TOF MS) was used to identify the bacterial colonies to the species level. Material from 1 to 3 pure-cultured colonies was smeared directly onto a polished steel target (Bruker Daltonik GmbH, Bremen, Germany), covered with $1 \mu \mathrm{L}$ of $\alpha$-cyano-4-hydroxycinnamic acid (HCCA) matrix (Bruker Daltonik $\mathrm{GmbH}$ ), prepared according to the manufacturer's instructions, and allowed to dry at room temperature. MALDI-TOF MS analysis was performed using a Microflex LT System running version 4.1.60 of the BDAL database (Bruker Daltonik $\mathrm{GmbH}$ ). A positive species identification was defined as a MALDI-TOF MS score $\geq 2.00$ [27]. Isolates identified with low confidence (MALDI-TOF MS scores between 1.70 and 1.99) were retested using the direct transfer-formic acid method [28], where $1 \mu \mathrm{L}$ of $70 \%$ formic acid (Sigma-Aldrich, Steinheim, Germany) was added to the bacteria on the target spot and allowed to air dry before matrix solution was added and analysis performed. A maximum of five confirmed S. suis isolates per pig were preserved at $-70{ }^{\circ} \mathrm{C}$, and later one isolate per pig was randomly selected for serotyping and antimicrobial susceptibility testing.

\section{Serotyping by latex agglutination}

Isolates were serotyped by latex agglutination [20,29] using the commercially available Immulex ${ }^{\mathrm{TM}} S$. suis kit (SSI Diagnostica A/S, Hillerød, Denmark) according to the manufacturer's instructions. The test identifies serotypes 1 through 16 separately, and groups serotypes 17 through 34 together. Briefly, $1 \mu \mathrm{L}$ of colony material, pure-cultured on $5 \%$ horse blood agar at $37{ }^{\circ} \mathrm{C}$ in $5 \%$ $\mathrm{CO}_{2}$ overnight, was suspended in $250 \mu \mathrm{L}$ of sterile saline before mixing $10 \mu \mathrm{L}$ of the suspension with $10 \mu \mathrm{L}$ of latex reagent. Agglutination that occurred within $60 \mathrm{~s}$ was interpreted as a positive reaction.

\section{Antimicrobial susceptibility testing}

Antimicrobial susceptibility testing was performed by broth microdilution using commercially available VetMIC GP-mo panels (National Veterinary Institute), according to the manufacturer's instructions. Isolates were cultured on $5 \%$ horse blood agar plates and incubated at $37{ }^{\circ} \mathrm{C}$ in $5 \% \mathrm{CO}_{2}$ overnight. Colonies were suspended in a $0.9 \%$ sterile saline solution to obtain an inoculum density of $5 \times 10^{5}$ colony-forming units per $\mathrm{mL}$ $(\mathrm{CFU} / \mathrm{mL})$, which was added to cation-adjusted Mueller-Hinton broth (National Veterinary Institute) supplemented with $3 \%$ lysed horse blood (Håtunalab $\mathrm{AB}$, Bro, Sweden). Each of the 96 wells of a VetMIC GP-mo plate was inoculated and incubated aerobically at $37{ }^{\circ} \mathrm{C}$ for 18-20 h. S. suis ATCC 43765 and Streptococcus pneumoniae ATCC 49619 were used as control strains and minimum inhibitory concentrations (MIC) were within the accepted quality control ranges. The MIC was recorded as the lowest concentration of an antimicrobial inhibiting visible bacterial growth. MICs of cefoxitin, cefalotin, ciprofloxacin, clindamycin, chloramphenicol, enrofloxacin, erythromycin, gentamycin, penicillin, tetracycline, trimethoprim, and trimethoprim/sulfamethoxazole were determined. The results were interpreted according to Clinical and Laboratory Standards Institute (CLSI) breakpoints for S. suis [30], where available.

\section{Results \\ Herds}

The case group consisted of seven farrow-to-finish herds and three piglet-producing herds. Out of the ten case herds, three were sow pool satellites from different sow pools. The control group consisted of eight farrow-tofinish herds, one gilt-producing, and one piglet-producing herd. Out of the ten control herds, two were specific pathogen-free (SPF) herds [31] and three were organic herds providing access to outside pastures or exercise yards for the pigs. All in-all out production was practiced consistently in all but one case and one control herd. The 
time for which the nursery pig barns were allowed to sit empty between batches varied between and within herds, in the case group from 0 to 21 days and in the control group from 0 to 7 days.

Clinical signs indicative of meningitis predominated in eight out of ten case herds, while two herds reported respiratory signs and acute deaths due to S. suis. All herds had recorded at least one case during the month preceding the sampling. At the interviews, three control herds reported that single pigs with clinical signs consistent

Table 1 Environmental parameters investigated in 20 Swedish pig herds with (case herds) and without (control herds) a history of Streptococcus suis-infections in grower pigs

\begin{tabular}{|c|c|c|c|c|c|}
\hline \multirow[t]{2}{*}{ Environmental parameters } & \multicolumn{2}{|c|}{$\begin{array}{l}\text { Control } \\
\text { herds } \\
(n=9)^{a}\end{array}$} & \multicolumn{2}{|c|}{$\begin{array}{l}\text { Case herds } \\
(\mathrm{n}=10)\end{array}$} & \multirow[t]{2}{*}{$P_{\text {value }}{ }^{b}$} \\
\hline & Mean & SD & Mean & SD & \\
\hline Temperature $\left({ }^{\circ} \mathrm{C}\right)$ & 20.4 & 3.42 & 19.5 & 3.95 & 0.59 \\
\hline Carbon dioxide (ppm) & 1622 & 950 & 1550 & 695 & 0.85 \\
\hline Ammonia in pens, mean (ppm) & 6.6 & 3.3 & 6.6 & 2.6 & 0.63 \\
\hline Air relative humidity (\%) & 55.9 & 17.5 & 58.4 & 12.4 & 0.73 \\
\hline $\begin{array}{l}\text { Air velocity (solid floor or deep } \\
\text { straw bedding), mean (m/s) }\end{array}$ & 0.10 & 0.05 & 0.09 & 0.03 & 0.34 \\
\hline $\begin{array}{l}\text { Air velocity (slatted floor), mean } \\
(\mathrm{m} / \mathrm{s})^{c}\end{array}$ & 0.14 & 0.08 & 0.07 & 0.03 & 0.10 \\
\hline
\end{tabular}

a Biosecurity rules in one herd prohibited measuring equipment being brought in

${ }^{\mathrm{b}} \mathrm{P}$ values were calculated using Welch's t-test. $\mathrm{P}<0.05$ was considered significant

c Herds using deep straw bedding not included, leaving control herds $n=6$ and case herds $n=9$ with an S. suis-infection had been observed by the farmers on single occasions. These potential cases had however not been clinically confirmed by the herd health veterinarians.

There were no significant differences between case and control herds in the environmental parameters measured (Table 1). Taking the farm owners' reports into account and reclassifying the three control herds reporting occasional cases as case herds, did not affect these results.

No significant differences were found between the case and control herds regarding the production data parameters (Table 2). However, reclassifying the three control herds reporting occasional cases as case herds resulted in the number of sows farrowing per batch being significantly lower $(P=0.01)$ in the control herds $(n=7$; mean 22.7, SD 12.5) than in the case herds $(n=13$; mean 40.1, SD 13.0).

The total number of sows in the sow pools ranged from 1000 to 1700 , with between 40 and 55 sows farrowing in each batch at the sampled satellite farms.

\section{Bacterial sampling}

Streptococcus suis was isolated from at least eight out of ten (mean 9.5, SD 0.7) of the sampled animals in each control herd, and from at least eight out of ten (mean 9.5, SD 0.7) of the sampled animals in each case herd. In total, S. suis was isolated from $95 \%$ (190 out of 200) of the sampled animals included in the study.

\section{Serotyping}

Latex agglutination was performed on 189 out of 190 isolates (one isolate could not be re-cultivated for analysis). A majority of the isolates $(81.5 \%, 154$ out of 189)

Table 2 Production data from 20 Swedish pig herds with (case herds) and without (control herds) a history of Streptococcus suis-infections in grower pigs

\begin{tabular}{|c|c|c|c|c|c|c|c|c|}
\hline \multirow[t]{2}{*}{ Production parameters } & \multirow{2}{*}{$\begin{array}{l}\text { Sweden } 2017^{a} \\
\text { Mean }\end{array}$} & \multicolumn{3}{|c|}{ Control herds } & \multicolumn{3}{|c|}{ Case herds } & \multirow[t]{2}{*}{$P$ value } \\
\hline & & $\mathbf{n}$ & Mean & SD & $\mathbf{n}$ & Mean & SD & \\
\hline Sows in production ${ }^{b}$ & 354 & 9 & 223.1 & 178.8 & 7 & 424.3 & 345.9 & 0.15 \\
\hline Sows farrowing per batch & $\mathrm{n} / \mathrm{a}$ & 10 & 28.7 & 14.2 & 10 & 39.3 & 14.8 & 0.12 \\
\hline Litters/sow/year $^{\mathrm{b}}$ & 2.24 & 6 & 2.12 & 0.27 & 6 & 2.20 & 0.06 & 0.49 \\
\hline Piglets born alive/litter & 14.3 & 7 & 14.0 & 0.9 & 8 & 14.5 & 0.7 & 0.34 \\
\hline Pigs weaned/litter ${ }^{c}$ & 11.9 & 7 & 11.3 & 1.1 & 8 & 11.9 & 0.7 & 0.22 \\
\hline Pigs weaned/sow/year ${ }^{b}$ & 26.6 & 6 & 24.0 & 4.6 & 6 & 26.6 & 1.4 & 0.24 \\
\hline Age at weaning (days) & 32.8 & 10 & 36.0 & 4.2 & 10 & 33.2 & 3.3 & 0.11 \\
\hline Gilt recruitment (\%) & 24.8 & 9 & 25.7 & 9.5 & 8 & 29.0 & 5.5 & 0.40 \\
\hline Farrowing interval (weeks) & $\mathrm{n} / \mathrm{a}$ & 10 & 3.4 & 1.7 & 10 & 2.5 & 1.1 & 0.18 \\
\hline
\end{tabular}

All data parameters were not available for all herds ( $n=$ number of herds included)

a Mean values for Sweden according to the InterPIG report 2018 [49]

b Sow pools not included

c Nurse sows were used in one of the control herds and six of the case herds 
exhibited insufficient or no agglutination and were therefore serologically non-typeable. The percentage of non-typeable isolates did not differ $(82.1 \%$ and $80.9 \%$, respectively) between case and control herds. The distribution of serotypes is shown in Fig. 1.

Serotype 5 was detected only in one case herd, whereas serotypes $3,4,7,9,10$, and 16 were detected only in the control herds. The isolates of serotypes 3, 4, 7, 10, and 16 were from one herd each, whereas serotype 9 was found in two herds. Serotypes 11, 15, and 17-34 were detected in both case and control herds.

Reclassification of the three previously mentioned control herds with occasional single cases of suspected $S$. suis-infections as case herds, resulted in one isolate from each of the serotypes $3,7,9,15$, and 16 being included in the case group.

\section{Antimicrobial susceptibility testing}

Antimicrobial susceptibility testing (Table 3 ) was performed on 188 of the 190 isolates obtained from clinically healthy pigs (two isolates could not be re-cultivated

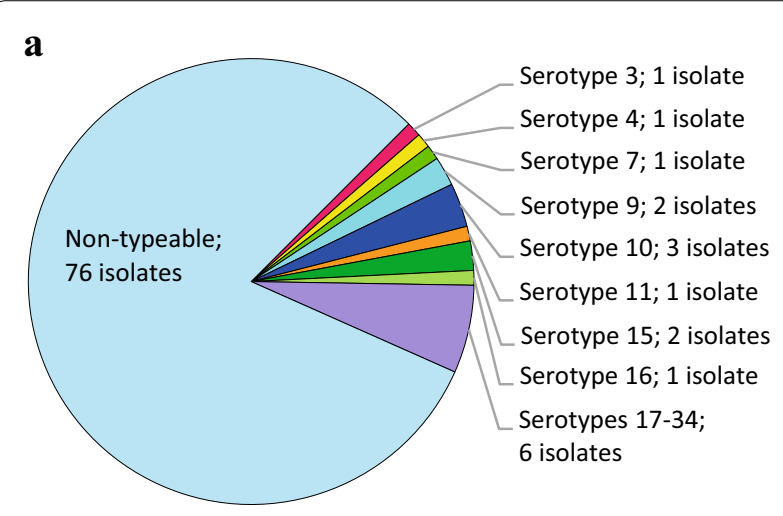

b

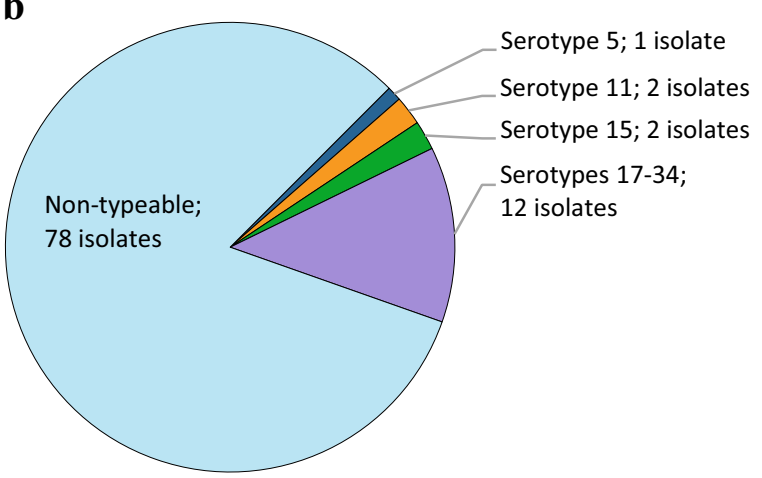

Fig. 1 Serotypes of Streptococcus suis isolated from the tonsils of clinically healthy 8-13-week-old grower pigs $(n=189)$ in Sweden. One isolate per pig was tested with latex agglutination. a Isolates $(n=94)$ from ten control herds with no history of S. suis-infections. $\mathbf{b}$ Isolates $(n=95)$ from ten case herds with a history of S. suis-infections for analysis). Susceptibility to penicillin was determined for 184 isolates (four isolates were not able to grow in the presence of the citric acid-containing buffer used for penicillin).

Several isolates $(9.2 \%, 17$ out of 184$)$ were classified as intermediate, and 3.8\% (7 out of 184) were resistant to penicillin. A majority of these not susceptible isolates $(87.5 \%, 21$ out of 24$)$, including all of the resistant isolates, originated from the case herds. The percentage of isolates not susceptible to enrofloxacin was $27.7 \%$ in the case group and $21.3 \%$ in the control group while the percentages of isolates not susceptible to tetracycline were similar in the two groups, at $100 \%$ and $98.9 \%$, respectively.

\section{Discussion}

Compared to the limited historical data available [32, 33], S. suis was isolated from a higher percentage than expected of clinically healthy Swedish grower pigs in both case and control herds. There was no difference in the percentage of carriers between the groups, and interestingly, the conventional herds did not differ in this respect from the closed SPF-herds or the organic herds with lower stocking density and outdoor access.

In contrast to previous studies on Swedish isolates [33, 34] the present study reports the occurrence of reduced susceptibility and resistance to penicillin. This is notable since penicillin resistance in S. suis is generally reported to be uncommon [16], and since Sweden has very low sales of antimicrobials for the use in food-producing animals [35]. In Sweden, benzylpenicillin is the most common antibiotic sold for the use in pig production, and in 2014 the consumption of antibiotics for pigs consisted of $75 \%$ products for injection, of which $60 \%$ were products containing benzylpenicillin [36]. A majority of the not susceptible isolates originated from case herds, which may be because of potentially higher use of antibiotic substances in these herds.

Despite the low Swedish sales of tetracyclines, as compared to sales in other European countries [35, 37], the present study demonstrates a very high percentage of isolates, $100 \%$ of isolates from the case group and $98.9 \%$ isolates from the control group, to be "not susceptible" i.e. intermediate or resistant, to tetracycline. Out of all the tested isolates, $88.4 \%$ were resistant to tetracycline, which is markedly higher than the 7.7\% reported in 1998 [33], and the 82.0\% reported in 2017 [34].

Using the CLSI breakpoints defined for enrofloxacin [30], 73.4\% of the isolates were classified as susceptible. It is of note that the breakpoint has been determined for a dose of $7.5 \mathrm{mg} / \mathrm{kg}$ [38], and it is not valid for lower dosages such as the one authorized in Sweden $(5 \mathrm{mg} / \mathrm{kg})$. 
Table 3 Antimicrobial susceptibility of 188 Streptococcus suis isolates from clinically healthy Swedish grower pigs from ten control herds without a history of Streptococcus suis-infections and ten case herds with a history of Streptococcus suis-infections in grower pigs

\begin{tabular}{|c|c|c|c|c|c|c|c|c|c|c|c|c|c|}
\hline \multirow{3}{*}{$\begin{array}{c}\text { Antimicrobial } \\
\text { agent }\end{array}$} & \multirow{3}{*}{$\begin{array}{c}\text { Resistance (\%) } \\
\text { 2018-2019 }\end{array}$} & \multicolumn{12}{|c|}{ Streptococcus suis } \\
\hline & & \multicolumn{12}{|c|}{ Distribution (\%) of MICs (mg/L) } \\
\hline & & $\leq 0.03$ & 0.06 & 0.12 & 0.25 & 0.5 & 1 & 2 & 4 & 8 & 16 & 32 & $\geq 64$ \\
\hline \multicolumn{14}{|c|}{ 3a) Distribution of MICs and occurrence of resistance in S. suis $(n=94)$ from control herds } \\
\hline Cefalotin & & & & 1.1 & 23.4 & 27.7 & 29.8 & 11.7 & 6.4 & & & & \\
\hline Cefoxitin & & & & & 1.1 & 5.3 & 9.6 & 18.1 & 21.3 & (44.7) & & & \\
\hline Chloramphenicol & & & & & 0 & 0 & 4.3 & 35.1 & 60.6 & 0 & 0 & 0 & \\
\hline Ciprofloxacin & & & & 0 & 17.0 & 62.8 & 16.0 & 3.2 & 1.1 & & & & \\
\hline Clindamycin & & & & & 26.6 & 4.3 & 2.1 & 1.1 & 8.5 & 20.2 & 5.3 & 31.9 & \\
\hline Enrofloxacin & 2.1 & & & 0 & 16.0 & 62.8 & 19.1 & 2.1 & 0 & & & & \\
\hline Erythromycin & & & & & 66.0 & 0 & 0 & 3.2 & 5.3 & 1.1 & 2.1 & (22.3) & \\
\hline Gentamycin & & & & 0 & 1.1 & 7.4 & 30.9 & 38.3 & 22.3 & 0 & 0 & & \\
\hline Penicillin $^{a}$ & 0 & 34.4 & 37.6 & 19.4 & 5.4 & 3.2 & 0 & 0 & 0 & & & & \\
\hline Tetracycline & 85.1 & & & & & 1.1 & 13.8 & 28.7 & 20.2 & 7.4 & 1.1 & 23.4 & 4.3 \\
\hline Trimethoprim & & & & & 68.1 & 4.3 & 3.2 & 0 & 7.4 & 7.4 & 9.6 & & \\
\hline Trim/Sulf ${ }^{b}$ & & & & 78.7 & 3.2 & 3.2 & 4.3 & 7.4 & 1.1 & 2.1 & & & \\
\hline
\end{tabular}

3b) Distribution of MICs and occurrence of resistance in S. suis $(n=94)$ from case herds

\begin{tabular}{|c|c|c|c|c|c|c|c|c|c|c|c|c|c|}
\hline Cefalotin & & & & 4.3 & 11.7 & 11.7 & 29.8 & 26.6 & 13.8 & (2.1) & & & \\
\hline Cefoxitin & & & & & 8.5 & 0 & 6.4 & 5.3 & 16.0 & (63.8) & & & \\
\hline Chloramphenicol & & & & & 0 & 2.1 & 3.2 & 28.7 & 61.7 & 4.3 & 0 & 0 & \\
\hline Ciprofloxacin & & & & 1.1 & 14.9 & 56.4 & 19.1 & 6.4 & 2.1 & & & & \\
\hline Clindamycin & & & & & 26.6 & 5.3 & 2.1 & 4.3 & 1.1 & 20.2 & 9.6 & 30.9 & \\
\hline Enrofloxacin & 8.5 & & & 1.1 & 14.9 & 56.4 & 19.1 & 6.4 & 2.1 & & & & \\
\hline Erythromycin & & & & & 59.6 & 4.3 & 2.1 & 1.1 & 4.3 & 2.1 & 3.2 & (23.4) & \\
\hline Gentamycin & & & & 1.1 & 0 & 6.4 & 34.0 & 35.1 & 21.3 & 2.1 & 0 & & \\
\hline Penicillin $^{c}$ & 7.7 & 18.7 & 17.6 & 16.5 & 24.2 & 15.4 & 5.5 & 2.2 & 0 & & & & \\
\hline Tetracycline & 91.5 & & & & & 0 & 8.5 & 17.0 & 22.3 & 6.4 & 1.1 & 35.1 & 9.6 \\
\hline Trimethoprim & & & & & 53.2 & 1.1 & 6.4 & 11.7 & 4.3 & 4.3 & 19.1 & & \\
\hline Trim/Sulf ${ }^{b}$ & & & & 60.6 & 8.5 & 8.5 & 7.4 & 10.6 & 2.1 & 2.1 & & & \\
\hline
\end{tabular}

Isolates from (3a) case herds and (3b) control herds were obtained during 2018-2019 and tested using broth microdilution. Species-specific breakpoints according to CLSI 2018 [30] are indicated with single vertical lines (sensitive) and double vertical lines (resistant). Values for the lowest concentration tested indicate MICs lower than or equal to the lowest concentration within the range. Parentheses indicate isolates with MICs above the dilution range included in the test panel

${ }^{\mathrm{a}} \mathrm{n}=93$ in the case of penicillin

b Concentration for trimethoprim given, tested in combination with sulfamethoxazole in a concentration ratio of 1:20

c $\mathrm{n}=91$ in the case of penicillin 
Thus, the clinical usefulness of enrofloxacin for the treatment of S. suis infections is questionable.

All of the isolates investigated originated from clinically healthy pigs, and several previous studies have also shown that resistance to several classes of antibiotics is more common in non-clinical isolates than in isolates from diseased pigs [39-42]. It must also be considered that differences in the sampling strategies, susceptibility testing methodologies, and interpretive criteria applied, complicate comparisons of antimicrobial susceptibility data from different studies. Additionally, the lack of species-specific veterinary clinical breakpoints for several classes of antibiotics hampers the clinical interpretation of the results.

Environmental factors such as higher outside temperature, temperature fluctuations, and a relative humidity of $>70 \%$, have previously been associated with a higher carriership of S. suis in clinically healthy pigs $[7,8]$. In the present study, the relative humidity and temperature in the room were measured once before bacterial sampling commenced, and no association was found between these parameters and the carriership of S. suis. Temperature logging, outside and in the pig barn, over a longer period of time and in a greater number of herds may be considered in the future when assessing possible diseasetriggering factors.

In addition, none of the investigated production factors differed significantly between case and control herds. However, if the three herds that had experienced single clinical cases of presumptive $S$. suis-infections were reclassified as case herds, the number of sows farrowing per batch was significantly higher in this group. Since the number of routes of transmission increases with an increasing number of individuals this might indicate that the group size is of importance. However, production data was not available for some herds, and care should be taken when interpreting these results.

The herds in the study were included in the case or control group solely based on their herd health veterinarian's assessment, as judged by the clinical picture and laboratory results. The few participating SPF- and organic farms were all found in the control group, which could indicate that clinical problems with $S$. suis are less common problem in these herds. However this interesting observation needs further investigations.

Several of the most commonly disease-associated $S$. suis serotypes, e.g. serotypes 9,3 , and 7 , were detected in clinically healthy pigs this study. S. suis is often considered part of the normal flora of the tonsils, and although certain serotypes are more often associated with disease, virulence can also vary within serotypes [43]. The diversity among the serotypes was lower in the case herds than in the control herds; four and nine serotypes, respectively. It is, however, difficult to draw any conclusions based on the present results. A majority $(81.5 \%, 154$ out of 189) of the investigated isolates were non-typeable using the latex agglutination method. This result may be due to poor sensitivity of the method used but is in accordance with several previous studies that, depending on the method used, have demonstrated up to $67 \%$ of isolates from clinically healthy pigs to be non-typeable [40, 43-45]. These isolates may be non-encapsulated or possess novel capsular polysaccharide loci [46]. The serotype group 17-34 encompasses six serotypes $(20,22,26$, 32,33 , and 34) that have been reclassified as S. parasuis, $S$. orisratti, and $S$. ruminantium [11, 12, 47]. Thus, further studies are needed to assess the virulence of these isolates. Other serotyping methods, e.g. in silico serotyping based on whole-genome sequencing, may be useful to further investigate the serotypes present in Sweden.

The perceived low incidence of clinical disease in Sweden may be due to low virulence of the strains present, or it may be related to other factors such as a high weaning age, a legislated minimum space allowance for growing pigs that is higher than the EU minimum $[25,48]$, or to the generally high health standard of pig herds, e.g. the freedom from PRRS virus [23]. There is however also the possibility that $S$. suis-infection may be underreported or misdiagnosed, and that the pathogen might be a more common cause of disease than previously acknowledged. Further, the possibility of the MALDI-TOF MS method generating false-positive results cannot be excluded.

\section{Conclusion}

This study shows S. suis to be more common in Swedish pig herds than previously estimated, and for the first time reports the presence of Swedish isolates resistant to penicillin. Several of the most commonly disease-associated serotypes were isolated from clinically healthy grower pigs, although a large number of isolates were serologically non-typeable using latex agglutination. Further studies are needed to investigate the serotypes and virulence of these isolates. No association was noted between the environmental factors investigated and the carriership of S. suis in clinically healthy grower pigs.

\footnotetext{
Abbreviations

CFU: Colony-forming units; CLSI: Clinical \& Laboratory Standards Institute; COBA: Colistin-oxolinic acid-blood agar; HCCA: a-Cyano-4-hydroxycinnamic acid; MALDI-TOF MS: Matrix-assisted laser desorption ionization-time of flight mass spectrometry; MIC: Minimum inhibitory concentration; PRRS: Porcine reproductive and respiratory syndrome; SPF: Specific pathogen free, i.e. free from infections with Mycoplasma hyopneumoniae, Actinobacillus pleuropneumoniae, toxigenic Pasteurella multocida, Brachyspira hyodysenteriae,
} 
swine influenza virus, and Sarcoptes scabiei. SPF production is also free from the following pathogens which are not present in Sweden: African swine fever virus, Aujeszky's disease virus, Brucella species, classical swine fever virus, foot and mouth disease virus, Japanese encephalitis virus, porcine epidemic diarrhoea virus, porcine reproductive and respiratory syndrome virus, rabies virus, swine vesicular disease virus, and transmissible gastroenteritis virus.

\section{Acknowledgements}

The authors are grateful to Robert Söderlund for his assistance in planning the study, Lise-Lotte Fernström, Boel Harbom, and Moa Skarin for their skilled technical assistance, and Nils Lundeheim for statistical support. The authors would also like to thank all participating farmers and the veterinarians at Farm and Animal Health for their help and kind support.

\section{Prior publication}

Data has not been published previously.

\section{Authors' contributions}

All authors contributed to the design of the study. AW and MJ carried out the sampling. AW performed the laboratory work with support from AA and $A B$. AW wrote the manuscript with support from MJ. $A A, A B, M S$, and $B G$ contributed to finalizing the manuscript. All authors read and approved the final manuscript.

\section{Funding}

This work was funded by FORMAS Grant dnr 2016-01118. The funding body had no role in the study design, collection of samples, analysis, interpretation, or preparation of the manuscript. Open access funding provided by Swedish University of Agricultural Sciences.

\section{Availability of data and materials}

The datasets used and/or analysed during the current study are available from the corresponding author on reasonable request.

\section{Ethics approval and consent to participate}

The study was approved by the Ethics Committee for Animal Experimentation, Uppsala, Sweden (Dnr 5.8.18-15404). Informed consent from the farmers was obtained before the collection of samples and production data from the herds.

\section{Consent for publication}

Not applicable.

\section{Competing interests}

The authors declare that they have no competing interests.

\section{Author details}

${ }_{1}^{1}$ Department of Clinical Sciences, Swedish University of Agricultural Sciences (SLU), Box 7054, 75007 Uppsala, Sweden. ${ }^{2}$ Department of Microbiology, National Veterinary Institute (SVA), 75189 Uppsala, Sweden. ${ }^{3}$ Department of Animal Health and Antimicrobial Strategies, National Veterinary Institute (SVA), 75189 Uppsala, Sweden. ${ }^{4}$ Department of Biomedical Science and Veterinary Public Health, Swedish University of Agricultural Sciences (SLU), Box 7036, 75007 Uppsala, Sweden.

Received: 4 March 2020 Accepted: 15 June 2020

Published online: 24 June 2020

\section{References}

1. Clifton-Hadley FA. Streptococcus suis type 2 infections. Br Vet J. 1983;139:1-5.

2. Lun Z-R, Wang Q-P, Chen X-G, Li A-X, Zhu X-Q. Streptococcus suis: an emerging zoonotic pathogen. Lancet Infect Dis. 2007;7:201-9.

3. Devriese LA, Hommez J, Pot B, Haesebrouck F. Identification and composition of the streptococcal and enterococcal flora of tonsils, intestines and faeces of pigs. J Appl Bacteriol. 1994;77:31-6.

4. Arends JP, Hartwig N, Rudolphy M, Zanen HC. Carrier rate of Streptococcus suis capsular type 2 in palatine tonsils of slaughtered pigs. J Clin Microbiol. 1984;20:945-7.
5. Dekker N, Bouma A, Daemen I, Klinkenberg D, Leengoed LV, Wagenaar $J$ A, et al. Effect of spatial separation of pigs on spread of Streptococcus suis serotype 9. PLOS ONE. 2013;8:e61339.

6. Amass SF, Clark LK, Knox K, Wu CC, Hill MA. Streptococcus suis colonization of piglets during parturition. Swine Health Prod. 1996;4:269-72.

7. Zou G, Zhou J, Xiao R, Zhang L, Cheng Y, Jin H, et al. Effects of environmental and management-associated factors on prevalence and diversity of Streptococcus suis in clinically healthy pig herds in China and the United Kingdom. Appl Environ Microb. 2018;84:e02590-17.

8. Dee SA, Carlson AR, Winkelman NL, Corey MM. Effect of management practices on the Streptococcus suis carrier rate in nursery swine. J Am Vet Med Assoc. 1993;203:295-9.

9. Galina L, Pijoan C, Sitjar M, Christianson WT, Rossow K, Collins JE. Interaction between Streptococcus suis serotype 2 and porcine reproductive and respiratory syndrome virus in specific pathogen-free piglets. Vet Rec. 1994;134:60-4.

10. Chatellier S, Harel J, Zhang Y, Gottschalk M, Higgins R, Devriese LA, et al. Phylogenetic diversity of Streptococcus suis strains of various serotypes as revealed by 165 rRNA gene sequence comparison. Int J Syst Bacteriol. 1998:48(Pt 2):581-9.

11. Hill JE, Gottschalk M, Brousseau R, Harel J, Hemmingsen SM, Goh SH. Biochemical analysis, cpn60 and $16 \mathrm{~S}$ rDNA sequence data indicate that Streptococcus suis serotypes 32 and 34, isolated from pigs, are Streptococcus orisratti. Vet Microbiol. 2005;107:63-9.

12. Tien LHT, Nishibori T, Nishitani Y, Nomoto R, Osawa R. Reappraisal of the taxonomy of Streptococcus suis serotypes 20, 22, 26, and 33 based on DNA-DNA homology and sodA and recN phylogenies. Vet Microbiol. 2013;162:842-9.

13. Goyette-Desjardins G, Auger JP, Xu J, Segura M, Gottschalk M. Streptococcus suis, an important pig pathogen and emerging zoonotic agentan update on the worldwide distribution based on serotyping and sequence typing. Emerg Microbes Infect. 2014;3:e45.

14. Flores JLM, Higgins R, D'Allaire S, Charette R, Boudreau M, Gottschalk M. Distribution of the different capsular types of Streptococcus suis in nineteen swine nurseries. Can Vet J. 1993;34:170.

15. Reams RY, Harrington DD, Glickman LT, Thacker HL, Bowersock TL. Multiple serotypes and strains of Streptococcus suis in naturally infected swine herds. J Vet Diagn Investig. 1996;8:119-21.

16. Varela NP, Gadbois P, Thibault C, Gottschalk M, Dick P, Wilson J. Antimicrobial resistance and prudent drug use for Streptococcus suis. Anim Health Res Rev. 2013;14:68-77.

17. Abaas S, Mårtensson L. Streptococcus suis påvisad även i svenska svinbesättningar. Svensk Veterinärtidning. 1986;38:237-8.

18. Atterholm I, Christensen P, Dahlquist E, Kronvall G. Ett fall av Streptococcus suis-meningit—en ny yrkessjukdom i Sverige? Läkartidningen. 1985;82:1.

19. Dalsjö A, Nilsson AC, Ramussen M. Complicated infection caused by Streptococcus suis serotype 14 transmitted from a wild boar. JMM Case Rep. 2014;1:e002105.

20. Gustavsson C, Rasmussen M. Septic arthritis caused by Streptococcus suis serotype 5 in pig farmer. Emerg Infect Dis. 2014;20:489-90.

21. Dalin AM, Gidlund K, Eliasson-Selling L. Post-mortem examination of genital organs from sows with reproductive disturbances in a sow-pool. Acta Vet Scand. 1997;38:253-62.

22. Djurskyddsförordning (SFS 2019:66) Stockholm: Näringsdepartementet.

23. National Veterinary Institute. Surveillance of infectious diseases in animals and humans in Sweden 2018. Uppsala, Sweden: National Veterinary Institute (SVA). Uppsala, Sweden. SVA:S rapportserie 56; ISSN 1654-7098.

24. R Core Team. R: a language and environment for statistical computing. Vienna: R Foundation for Statistical Computing; 2019.

25. Statens jordbruksverks föreskrifter och allmänna råd om grishållning inom lantbruket m.m. (SJVFS 2019:20) Jönköping: Jordbruksverket.

26. Kilpper-Bälz R, Schleifer KH. Streptococcus suis sp. nov., nom. rev. Int J Syst Bacteriol. 1987;37:160-2.

27. Perez-Sancho M, Vela Al, Garcia-Seco T, Gottschalk M, Dominguez L, Fernandez-Garayzabal JF. Assessment of MALDI-TOF MS as alternative tool for Streptococcus suis identification. Front Public Health. 2015;3:202.

28. Schulthess B, Brodner K, Bloemberg GV, Zbinden R, Bttger EC, Hombach M. Identification of gram-positive cocci by use of matrix-assisted laser desorption ionization-time of flight mass spectrometry: comparison of different preparation methods and implementation of a practical algorithm for routine diagnostics. J Clin Microbiol. 2013;51:1834-40. 
29. Afshar B, Broughton K, Creti R, Decheva A, Hufnagel M, Kriz P, et al. International external quality assurance for laboratory identification and typing of Streptococcus agalactiae (Group B streptococci). J Clin Microbiol. 2011;49:1475-82.

30. CLSI. Performance standards for antimicrobial disk and dilution susceptibility tests for bacteria isolated from animals. 4th ed. CLSI Supplement VET08. Wayne: Clinical and Laboratory Standards Institute; 2018.

31. Wallgren P, Vallgarda J. SPF husbandry_-presentation, definition and list of requirements. Svensk Veterinärtidning. 1993;45:733-5.

32. Sjölund $M$, Lindberg $M$, Pringle $M$, Harbom B, Unnerstad HE. Occurrence serotype and antibiotic susceptibility of Streptococcus suis isolates from healthy and diseased Swedish pigs. In: Proceedings of the 25th international pig veterinary society congress. June 11-14; 2018; Chongqing, China. 2018; p. 672.

33. Aarestrup FM, Rasmussen SR, Artursson K, Jensen NE. Trends in the resistance to antimicrobial agents of Streptococcus suis isolates from Denmark and Sweden. Vet Microbiol. 1998;63:71-80.

34. Public Health Agency of Sweden and National Veterinary Institute. Swedres-Svarm 2017. Consumption of antibiotics and occurrence of antibiotic resistance in Sweden. Solna/Uppsala ISSN 1650-6332; 2017.

35. European Medicines Agency. Sales of veterinary antimicrobial agents in 31 European countries in 2017 (EMA/294674/2019). European Medicines Agency; 2019.

36. Public Health Agency of Sweden and National Veterinary Institute. Swedres-Svarm 2014. Consumption of antibiotics and occurrence of antibiotic resistance in Sweden. Solna/Uppsala ISSN 1650-6332; 2014.

37. Public Health Agency of Sweden and National Veterinary Institute. Swedres-Svarm 2018. Consumption of antibiotics and occurrence of antibiotic resistance in Sweden. Solna/Uppsala ISSN 1650-6332; 2018.

38. CLSI. Understanding susceptibility data as a component of antimicrobial stewardship in veterinary settings. 1st ed. CLSI report VET09. Wayne: Clinical and Laboratory Standards Institute; 2019.

39. Zhang C, Zhang Z, Song L, Fan X, Wen F, Xu S, et al. Antimicrobial resistance profile and genotypic characteristics of Streptococcus suis capsular type 2 isolated from clinical carrier sows and diseased pigs in China. Biomed Res Int. 2015;2015:284303.

40. Soares TC, Paes AC, Megid J, Ribolla PE, Paduan Kdos S, Gottschalk M. Antimicrobial susceptibility of Streptococcus suis isolated from clinically healthy swine in Brazil. Can J Vet Res. 2014;78:145-9.
41. Hernandez-Garcia J, Wang J, Restif O, Holmes MA, Mather AE, Weinert $L A$, et al. Patterns of antimicrobial resistance in Streptococcus suis isolates from pigs with or without streptococcal disease in England between 2009 and 2014. Vet Microbiol. 2017;207:117-24.

42. Yongkiettrakul $S$, Maneerat $K$, Arechanajan B, Malila Y, Srimanote $P$, Gottschalk M, et al. Antimicrobial susceptibility of Streptococcus suis isolated from diseased pigs, asymptomatic pigs, and human patients in Thailand. BMC Vet Res. 2019;15:5.

43. Segura M, Fittipaldi N, Calzas C, Gottschalk M. Critical Streptococcus suis virulence factors: are they all really critical? Trends Microbiol. 2017;25:585-99.

44. Han DU, Choi C, Ham HJ, Jung JH, Cho WS, Kim J, et al. Prevalence, capsular type and antimicrobial susceptibility of Streptococcus suis isolated from slaughter pigs in Korea. Can J Vet Res. 2001;65:151-5.

45. Marois C, Le Devendec L, Gottschalk M, Kobisch M. Detection and molecular typing of Streptococcus suis in tonsils from live pigs in France. Can J Vet Res. 2007;71:14-22.

46. Qiu X, Bai X, Lan R, Zheng H, Xu J. Novel capsular polysaccharide loci and new diagnostic tools for high-throughput capsular gene typing in Streptococcus suis. Appl Environ Microb. 2016:82:7102-12.

47. Tohya M, Arai S, Tomida J, Watanabe T, Kawamura Y, Katsumi M, et al. Defining the taxonomic status of Streptococcus suis serotype 33: the proposal for Streptococcus ruminantium sp. nov. Int I Syst Evol Microbiol. 2017:67:3660-5.

48. Council Directive 91/630/EEC of 19 November 1991 laying down minimum standards for the protection of pigs.

49. Gård \& Djurhälsan. InterPIG Internationella rapporten 2018. Gård \& Djurhälsan. 2019. https://www.gardochdjurhalsan.se/wp-content/uploa ds/2019/11/internationella-rapporten-2018.pdf. Accessed 2 Mar 2020.

\section{Publisher's Note}

Springer Nature remains neutral with regard to jurisdictional claims in published maps and institutional affiliations.

Ready to submit your research? Choose BMC and benefit from:

- fast, convenient online submission

- thorough peer review by experienced researchers in your field

- rapid publication on acceptance

- support for research data, including large and complex data types

- gold Open Access which fosters wider collaboration and increased citations

- maximum visibility for your research: over $100 \mathrm{M}$ website views per year

At BMC, research is always in progress.

Learn more biomedcentral.com/submissions 